\title{
Response of Market Returns to Inflation News: Asymmetry Based on the Level of Inflation
}

\author{
Yasemin Ulu, ${ }^{1 *}$ \\ ${ }^{1}$ Department of Economics, Saginaw Valley State University, Saginaw, MI., USA \\ *Corresponding author: Department of Economics, Saginaw Valley State University, \\ Saginaw, MI., USA. E-mail: yasemin.ulu@gmail.com
}

Received: September 13, 2019 Accepted: October 17, 2019 Published: December 20, 2019

doi: 10.5296/rae.v11i4.16118ＵRL: https://doi.org/10.5296/rae.v11i4.16118

\begin{abstract}
Using daily data we look at S\&P500 returns to inflation news during the period 1980-2002, where we categorize the data into sub-periods based on the level of inflation and the phase of economic cycle. We find that although stock market's reaction to inflation news is generally negative, the response appears to depend on the level of prevailing inflation and phase of the business cycle. Specifically, we find that on the day of inflation announcement daily returns during periods of low inflation and low risks of recession respond positively to inflation news in recessionary states. Our results show that while high inflation weighs on market returns, low inflation creates positive returns opportunities when the economy faces low risks of recession. Asymmetric response of daily returns to inflation news depending on the level of inflation is an interesting novel finding.
\end{abstract}

Keywords: inflation news, market response, daily returns, S\&P 500, asymmetry 


\section{Introduction}

This paper examines if inflation news impacts daily market returns differently across various economic regimes which are defined by two high-profile macroeconomic risks: the level of inflation and risk of recession. Specifically, we examine if, on average, inflation announcements in recessionary states create positive returns opportunities during periods when background inflation and recession risks are both moderately low.

As is generally known in theoretical finance, two key effects on market returns derive from inflation and recession risks, commonly referred to as the "discount rate" and "dividend rate" effects.(Note 1) For example, high inflation means a high discount rate which implies low returns, while high risk of recession means a low dividend rate and thus low returns. The motivation for this inquiry is that the two main effects - discount rate and dividend rate effects - move differently with the level of inflation and the phase of the business cycle.

In particular, a period of low inflation favors the discount effect, and anticipation of economic recovery helps the dividend effect - together the two effects are likely to enhance market returns. In principle, the most favorable returns scenario is a regime where both the inflation level and recession risks happen to be low, such that the discount and dividend effects both work in the positive direction, yielding a significantly positive effect on returns. When inflation level and recession risks are not low, however, the discount and dividend effects may be negative, or offset each other so that returns are not affected.

In order to assess these claims, we identify macroeconomic regimes based on the level of inflation and risk of recession and check if market returns are differently impacted across regimes following inflation news. This allows us to study if there is asymmetry in returns and helps us categorize conditions under which returns are positively impacted.

Although, generally the negative effects of inflation on market returns are well known, that returns can be positively impacted by inflation news when inflation is low is a new finding and suggests the importance of the level of inflation and the state of the economy as important determinants of market returns. Looking at inflation news without reference to the two macroeconomic risks does not capture the full effect on market returns. The point we would like to emphasize is that the macroeconomic context, the level of inflation and the state of the economy, matters in an important way. Empirical results in this paper confirm that market returns react favorably to inflation news in recessionary states provided the economy is in the low inflation-recession regime. Our study therefore also suggests that a period of low inflation is fundamentally different from any other inflationary regime.

The stock market's reaction to inflation news has received much attention in the literature, though the findings remain somewhat ambiguous. Nelson (1976) and Fama and Schewert (1977) estimate significant negative response of stock returns to inflation, while Schewert (1981) observes that daily response of stock prices to unexpected inflation announcements is weak and slow during 1953-1958. Pearce and Roley (1985) find that daily stock price response to money stock (between 1977 and 1982) is significant, but the effects of Industrial Production, CPI and unemployment on prices are not significant. Similar results can be found in Jain (1988), McQueen and Roley (1993) and Hardouvelis (1987). 
Some of the recent studies in this area analyze stock market's response to macroeconomic news depending on the stage of the economic cycle, the idea being that returns are state dependentthat is, differently impacted in expansions versus recessions. These studies find that stock market's reaction to macroeconomic news is indeed state dependent [see McQueen and Roley (1993), Bae and Karolyi (1994), Fagher and Weigand (1998), and Andersen et al. (2005), among others]. Boyd et al (2005) using daily data find that a positive unemployment surprise is good news for stocks during expansions but bad news during economic contractions. In terms of inflation announcements, Adams et al (1999) find that the strength of the stock returns and unanticipated inflation relationship varies with the state of the economy and the direction of the news. Andersen et al (2005) using futures data find evidence that inflation news affects stock returns negatively in the high states. Alvi and Ulu (2019) using 5-minute post announcement high-frequency data conclude that the S\&P500, DJIA and Nasdaq100 returns respond to inflation surprises positively in the low states (recession) but negatively in the high states (expansion) during 1999-2003. More recently, Knif et al (2008) find evidence that depending on the economic state, positive and negative inflation shocks produce asymmetric effects. Their study is different in that they find asymmetry only after they group the positive and negative shocks. As they point out when negative and positive shocks are pooled the effects are washed out.

Our study is different from others and Knif et al. (2008) for three reasons. First, we define a macroeconomic regime by both the recession state as well as the level of inflation, whereas other studies that make reference to states do so only with respect to recessions versus expansions. The obvious argument for inclusion of both is that a comprehensive characterization of any macro regime requires that both macro risks be accounted for. The level of inflation clearly is a most noteworthy macroeconomic fundamental. Additionally, while it is well known that high inflation affects returns negatively through the usual "discount rate" effect, the impact of low inflation on market returns is less clearly understood. In our paper, the effects of inflation surprises are then assessed across the various macroeconomic regimes.

We find comparable results to Andersen et al (2005) that find evidence of negative effect of inflation surprises on stock returns in the high states, and Alvi and Ulu (2019), that concludes that the S\&P500, DJIA and Nasdaq100 returns respond to inflation surprises negatively in the high states (expansion) during 1999-2003, but positively in the low states (recession). Our results are also inline with Knif et al (2008) find evidence of asymmetric effect of negative and positive inflation shocks depending on the economic state. However, a direct comparison can't be made since our-study differs from above as we include "macroeconomic regimes" and levels of inflation.

Specifically, in comparison to other studies our results show that asymmetric effects exist depending on the level of background inflation and risks of recession, rather than only because of the recession state and the direction of inflation news. Second, after accounting for state dependence - recessions versus expansions - no paper in the existing literature has yet looked at the asymmetry in daily returns in high versus low inflation environments. That the combination of low inflation and low recession risks overturns the usual negative relationship between inflation news and market returns is an interesting finding that highlights the 
fundamental importance of low inflation in determining market returns. Third, the fact that regardless of the direction of the inflation shocks the inflation announcement effects endure at daily frequency, well beyond the initial half-hour window, is also a novel finding, which implies that the effects we describe are rather persistent compared to the findings reported in high-frequency studies.

In section 2 we describe the data and the model, section 3 presents the results and section 4 concludes.

\section{Data and the Model}

We use daily data on the day of the announcement for the period 1980:2-2002:09. To capture the economic phase, a recession coincident index (Stock and Watson, 1989) is used to account for recessions versus expansions. We use Money Market Survey data of Producer Price Index (PPI) expectations and actual levels of PPI to form inflation news, using PPI as proxy for inflation. The "surprise" is measured as the PPI announced at 8:30 (EST/EDT) (actual PPI) minus the expected PPI, which is the median survey expectation from Money Market Services.(Note 2) The MMS survey is widely used as a proxy for expectations in other research and is known to be unbiased and pass simple forecast rationality tests and is found to outperform naïve time series forecasts [Balduzzi et al (2001)]. On PPI announcement days when Industrial Production (IP) and Retail Sales (RS) announcements are also made, we include their surprises as well to account for the movements in the stock returns due to this news.

In order to classify whether the economy is in a recession or expansion, following Boyd et al (2005) we use the experimental coincident recession index (hereafter xric) constructed by Stock and Watson (1989). The recession index attaches an estimated probability to each month that indicates the likelihood that the economy is in recession, using four monthly series (industrial production, real personal income less transfer payments, real manufacturing and trade sales, and total employee hours in non-agricultural establishments).

We do not use the NBER's dating of contractions because it makes use of the information available at a later point in time and does not offer any monthly assessments of the state of the economy. In our analysis, the coincident recession index is a continuous measure and has the additional advantage that it makes use of the information available at that point in time and therefore reflects investor sentiments better. S\&P500 returns are constructed from S\&P500 close prices on the day before the announcement and the close prices of the day of the announcement.

\subsection{The Model}

To assess the effect of low inflation on returns we divide the sample into sub-periods based on the level of inflation (hereafter infl) and the extent of recession risk (xric hereafter) using the Bai-Perron $(1998,2003)$ change point test. Because the claim is that returns are differently impacted depending on inflation level and recession risks, we use a measure that incorporates 
both variables to identify the breakpoints, which we describe below.

The Bai-Perron change point test $(1998,2003)$ is designed to capture multiple structural changes occurring at unknown dates in a linear regression model estimated by least squares. This test enables us to identify if there are L vs. $\mathrm{L}+1$ unknown breaks and estimates the dates of the breaks. We denote the variable of interest as infl+xric to represent the measure of inflation plus recession risk and look for breaks in that series.

The conceptual underpinning of the choice of xric+infl is based on the fact that market returns are affected by both inflation risk and recession risk. When the economy is in a state of recession the prospect of recovery helps the dividend effect since investors are forward looking, and a low level of inflation helps the discount rate effect.(Note 3) Together, given recession and low inflation, the two effects positively impact market returns. To be sure, recession risks need to be low, otherwise the dividend effect is either weak or goes in the wrong direction, voiding the positive effects of low inflation. For example, if recession risk is very low it is possible the economy is already in a state of continuing expansion and the dividend effect is therefore weak; and if recession risk is very high investors may be uncertain about the depth of the recession and timing of recovery and consequently the dividend effect may remain negative.

In either case, low inflation alone may not be sufficient in generating positive returns. It is also helpful to note that we are referring to low but not very low inflation, because the latter may mean the economy is too close to deflation and the normal discount rate effects may not apply. When low recession risks prevail without inflation being low, however, the negative discount rate effect due to the latter may offset the positive dividend effect of low recession risks such that the overall impact on returns may not be positive.

Changes in xric+infl represent varying returns opportunities generated by the dividend and discount rate effects respectively. Of particular interest to this paper is the combination of low inflation coupled with low recession risks where we expect market returns to be positively impacted. For every other combination of inflation and recession risks the discount and dividend effects either lower returns, or roughly contradict each other leaving returns mostly unaffected. To check for robustness of our results we also use infl*xric as an alternative measure and find broadly similar conclusions.

After getting the break dates we divide the data into sub-periods based on these dates and estimate the effects on market returns. Following Boyd et al (2005) we estimate the following model for each sub-period.

$$
r_{t}=\beta_{0}+\beta_{1} X R I C_{t} \pi_{\text {surp }, t}+\beta_{2}\left(1-X R I C_{t}\right) \pi_{\text {surp }, t}+\varepsilon_{t}
$$

where is the daily return on S\&P500 on day $\mathrm{t}$ (announcement day), is the experimental coincident recession index that indicates the probability that the economy is in recession (Stock and Watson, 1989) and is the inflation surprise in month $t$, calculated as the difference between MMS survey expectations for PPI less the actual PPI (announcement at 8:30 EST). The estimated coefficient for shows the response of returns to inflation surprise in recessions and 
the estimated coefficient on denotes the returns reaction to inflation surprise in expansions. We also include IP surprises and RS surprises on days when they coincide with PPI announcements.

\section{Results}

Given the sub-periods picked by the Bai-Perron test, 1983:05, 1992:01, 1996:01, and 99:05, we see the following broad differences across regimes. Of the five sub-periods (also see Figure 1 and Figure 2), Period I (1980:02-1983:04) can be characterized as having very high inflation and very high xric values; period II (1983:05-1991:12) also has high inflation though with moderate xric values and period III (1992:01-1995:12) shows low level of inflation and low xric values. Period IV has low inflation but is associated with very low risks of recession, while $\mathrm{V}$ is characterized by low inflation but very high risks of recession. The last two regimes, additionally, have had several deflation entries, making the very low inflation too close to deflation to be of comfort to investors.(Note 4) In terms of inflation and risks of recession period III presents the ideal scenario - low inflation with low risk of recession-where positive effect on returns is postulated. Below are the estimation results for the sub-samples.

Table 1. Breaks Using Bai-Perron Test Where infl+xric is the Variable of Interest

\begin{tabular}{lllllll}
\hline & & Period1 & Period II & Period III & Period IV & Period V \\
& & $1980: 02-$ & $1983: 05-$ & $1992: 01-$ & $1996: 01-$ & $1999: 05-$ \\
Coefficient & Entire & $1983: 04$ & $1991: 12$ & $1995: 12$ & $1999: 04$ & $2002: 09$ \\
& Period & $38-$ & 103 & 45 & 39 & 40 \\
& & observations & observations & observations & observations & observations \\
\hline \multirow{2}{*}{$\hat{\beta}_{1}$} & -0.299 & -0.07 & -0.113 & $12.37^{* *}$ & 6.902 & -0.687 \\
& $(0.403)$ & $(0.4692)$ & $(1.2527)$ & $(6.072)$ & $(20.96)$ & $(0.718)$ \\
$\hat{\beta}_{2}$ & & & & & & 1.435 \\
& -0.467 & $-0.7905^{*}$ & $-1.045^{* *}$ & $-6.35^{* *}$ & 0.067 & $(0.815)$ \\
\hline
\end{tabular}

**significant at 5\% level, * significant at 10\% level respectively. Newey-West, HAC standard errors are in parentheses.

The estimated coefficients and t-statistics are presented in Table 1 for the entire sample and the sub-periods. For the full sample, where the level of inflation is not taken into account, we see negative, though insignificant coefficients both in recessions and expansions. For Period I, the inflation surprise coefficient is .79 with a negative sign and is significant at the $10 \%$ level during expansion months and insignificant during recession months. In Period II we find that the stock market's reaction is again insignificant during recession months and negative and significant at 5\% during expansions. Period III, which is the one of particular interest, shows positive and significant impact (at 5\% level) on returns during recessions with a coefficient of 
12.35; and the coefficient is negative and significant (-6.35 at 5\% significance) during expansions. This confirms that a regime of low inflation and low recession risks presents positive returns opportunities. Looking at the fourth and fifth periods, the coefficients are not significant. Interestingly, the result that returns are positively impacted in regime III also shows that the inflation-returns relation, which is known to be usually negative, is reversed in a low inflation environment when recession risk is generally low.

We also use infl*xric as an alternative measure to identify the various regimes and find support for our main hypothesis. The estimates are shown in the next table. The Bai-Perron test picks the following breaks in the infl*xric series using the supF test; five breaks are identified at $40,111,151,192,232$ which translate to the following six sub-periods shown below in Table 2 .

Table 2. Breaks Using Bai-Perron Test Where xric*inf is the Variable of Interest

\begin{tabular}{llllllll}
\hline & & Period1 & Period II & Period III & Period IV & Period V & Period VI \\
\cline { 3 - 7 } Coefficient & Entire & $1980: 02-$ & $1983: 05-$ & $1989: 05-$ & $1992: 08-$ & $1996: 01-$ & $1999: 05-$ \\
& Period & $1983: 04$ & $1989: 04$ & $1992: 07$ & $1995: 12$ & $1999: 04$ & $2002: 09$ \\
& & $38-$ & 71 & 38 & 39 & 39 & 40 \\
& & observations & observations & observations & observations & observations & observations \\
\hline \multirow{3}{*}{$\hat{\beta}_{1}$} & -0.299 & -0.07 & -8.563 & -0.6085 & $14.023^{*}$ & 6.9016 & -0.6863 \\
& $(0.403)$ & $(0.4692)$ & $(5.1434)$ & $(1.5245)$ & $(7.5356)$ & $(20.969)$ & $(0.7181)$ \\
$\hat{\beta}_{2}$ & & & & & & & $1.4346^{*}$ \\
\hline
\end{tabular}

** significant at 5\% level,* significant at $10 \%$ level respectively. Newey-West, HAC standard errors are in parentheses.

As seen above, the coefficient of inflation surprise is positive in period IV, the time period which mostly coincides with regime III in the previous table where inflation and recession risks are both low. In every other period either recession risk is not low and/or inflation level is not low-in periods 1-IV inflation levels are rather high, while in period V recession risk is very low and in period VI many entries are deflationary and recession risk is very high. This thus supports the results obtained by using xric+infl.(Note 5) 


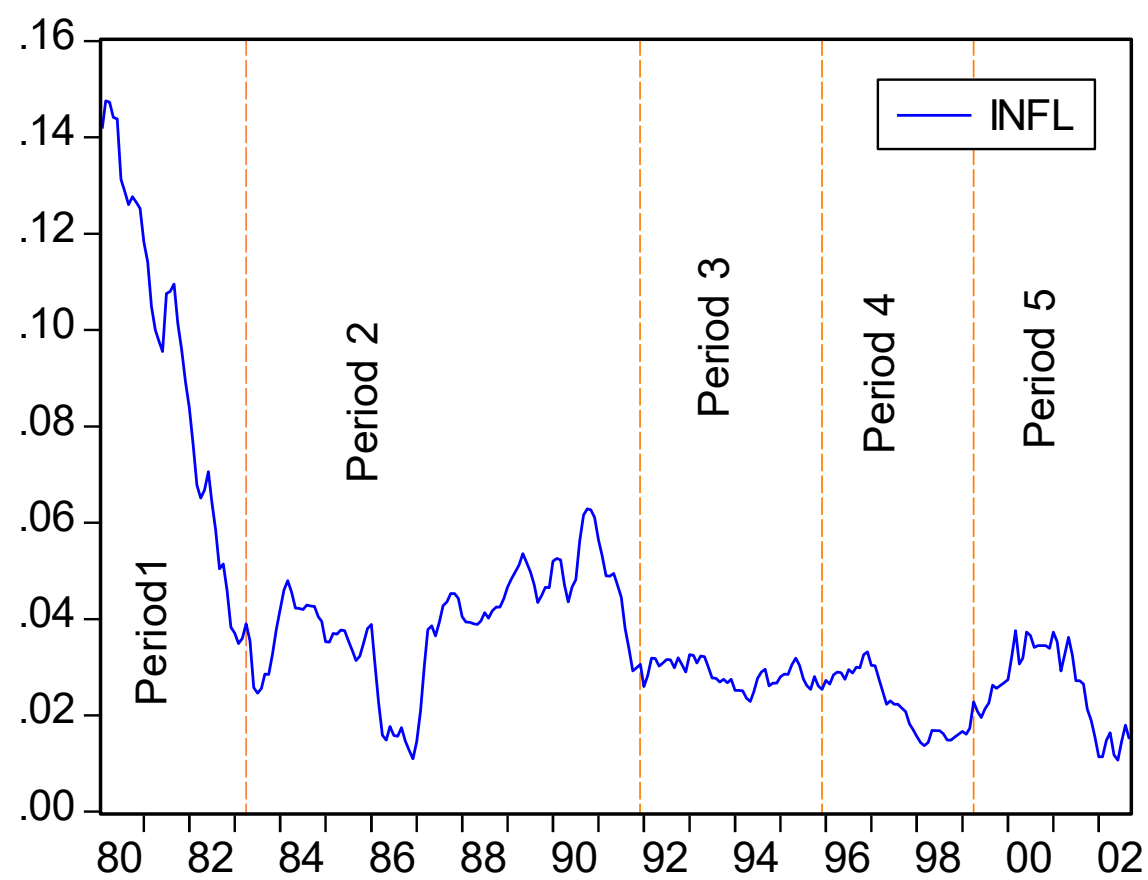

Figure 1. Inflation Rate: Inflation Data with Breakpoints Obtained by Bai-Perron Test on infl+xric (1980:02-2002:09)

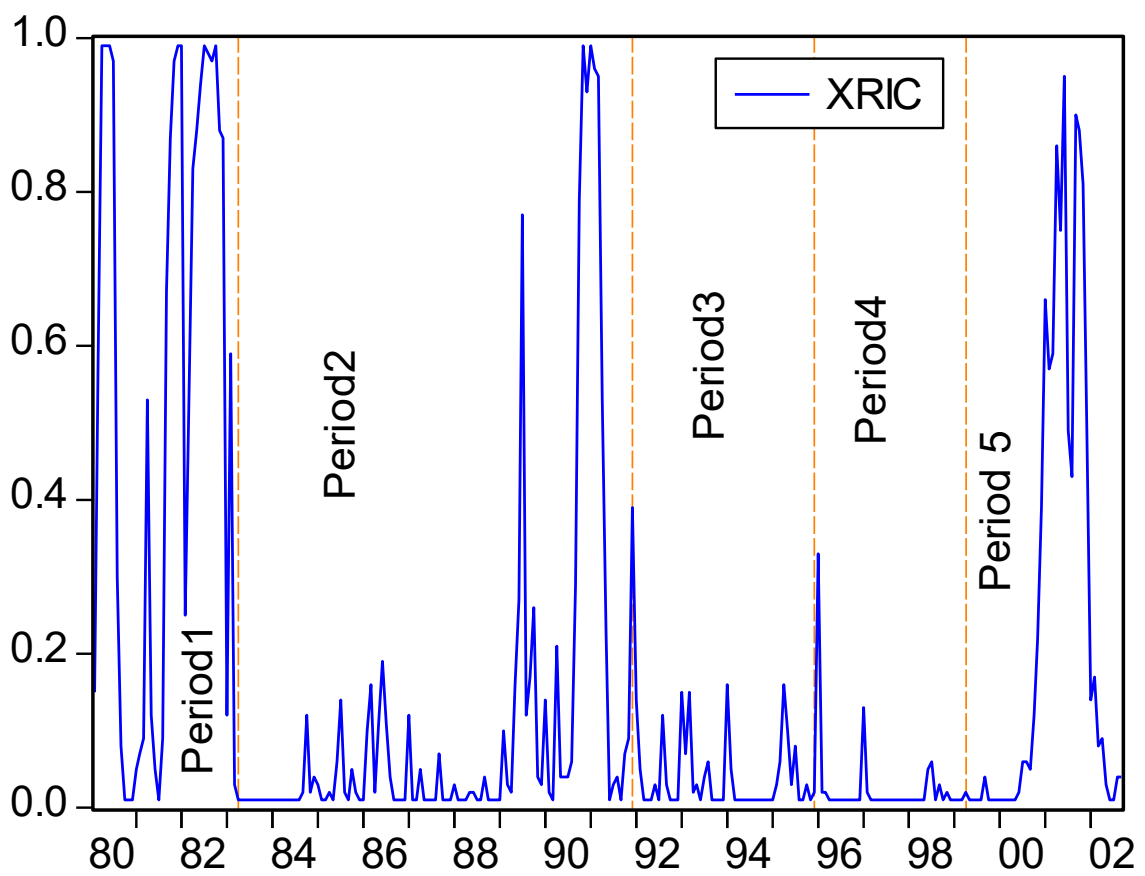

Figure 2. XRIC Index with Breakpoints Obtained by Bai-Perron Test on infl+xric 


\section{Conclusion}

Market returns are impacted by changes in discount rate and dividend rate - these effects however vary with the level of inflation and the phase of the business cycle. We study the effects of inflation news on market returns to examine if daily returns vary across different macroeconomic regimes and in particular exhibit asymmetry in low-inflation versus highinflation environments.

Specifically, we show that while inflation surprises generally affect returns negatively, that effect turns positive and significant when inflation is low, and the economy faces low recession risks.

It is interesting to note that deflation is not the same as low inflation in that the impact of inflation news on returns is not positive in recession states. Thus, both high inflation and deflation weigh on market returns, but the opposite is true in the event of low inflation when the economy is in recession states. The fact that regardless of the direction of shocks the effect of inflation surprises on stock returns is present in daily returns and is dependent on the level of prevailing inflation and the stage of the business cycle is quite striking and noteworthy, given that expectations are that markets adjust quickly to information.

In contrast to the literature's discussion of 'good news' and 'bad news' which are usually defined in terms of the direction of the shocks (inflation surprises in this case) and the state of the economy, this paper highlights a different perspective- 'good' and 'bad' macroeconomic regimes, where returns are positively and negatively impacted, respectively, depending on two major background macroeconomic risks: inflation level and recession risks. In terms of portfolio choice our study suggests interesting allocation strategies over different macroeconomic regimes. Of all possible configurations, the most favorable environment for returns is the one with low inflation and low risk of recession. The least favorable likely is the one where inflation and risk of recession are both high.

Though outside the scope of our study due to lack of observations, it is quite plausible that the 'global worst-case scenario' may be the one with high deflation and high risk of recession, where once the prospect of further rate cuts by the Federal Reserve is absent the economy faces overwhelmingly negative dividend effects.

\section{References}

Adams, G., McQueen, G., \& Wood, R. (2004). The Effects of Inflation News on HighFrequency Stock Returns. Journal of Business, 77(3), 547-574. http://dx.doi.org/10.1086/386530

Alvi, E., \& Ulu, Y. (2019). Inflation Surprise and Equity Returns Surrounding the 2001Recession: Are the Effects Asymmetric? The Open Journal of Economics and Finance.

Andersen, T. G., Bollerslev, T., Diebold, F. X., \& Vega, C. (2005). Real-Time Price Discovery in Stock, Bond and Foreign Exchange Markets. NBER Working Paper, 11, 312. 
Bae, K. H., \& Karolyi, G. A. (1994). Good News, Bad News, and International Spillovers of tock Return Volatility between Japan and the U.S. Pacific-Basin Finance Journal, 2, 405438. https://doi.org/10.1016/0927-538X(94)90003-5

Bai, J., \& Perron, P. (1998). Critical Values for Multiple Structural Change Tests. Econometrics Journal, 6, 72-78. https://doi.org/10.1111/1368-423X.00102

Bai, J., \& Perron, P. (2003). Estimating and Testing Linear Models with Multiple Structural Changes. Econometrica, 66, 47-78.

Balduzzi, P., Elton, E. J., \& Green, T. C. (2001). Economic News and Bond Prices: Evidence from the U.S. Treasury Market. Journal of Financial and Quantitative Analysis, 36, $523-$ 543. https://doi.org/10.2307/2676223

Boyd, J. H., Hu, J., \& Jagannathan, R. (2005). The Stock Market's Reaction to Unemployment News: Why Bad News is usually good for Stocks? The Journal of Finance, 60(2), 649. https://doi.org/10.1111/j.1540-6261.2005.00742.x

Fama, E. F., \& Schewert, G. W. (1977). Asset Returns and Inflation. Journal of Financial Economics, 5, 115-146. https://doi.org/10.1016/0304-405X(77)90014-9

Fargher, N., \& Weigand, R. (1998). Changes in the Stock Price Reaction of Small Firms to Common Information. Journal of Financial Research, 21, 105-121. https://doi.org/10.1111/j.1475-6803.1998.tb00272.x

Jain, P. (1988). Response of hourly stock prices and trading volume to economic news. Journal of Business, 61, April, 219-31.

Knif, J., Kolari, J., \& Pyynonen, S. (2008). Stock Market Reaction to good and bad inflation news. The Journal of Financial Research, XXXI(2).

McQueen, G., \& Roley, V. (1993). Stock prices, news and business conditions. Review of Financial Studies, 6, 683-707.

Nelson, C. R. (1976). Inflation and Rates of Return on Common Stock. Journal of Finance, 31, 471-483. https://doi.org/10.1111/j.1540-6261.1976.tb01900.x

Pearce, D. K., \& Roley, V. V. (1985). Stock Prices and Economic News. Journal of Business, $58,49-67$.

Schewert, G. W. (1981). The adjustment of stock prices to information about inflation. Journal of Finance, 36(March), 5-29. https://doi.org/10.1111/j.1540-6261.1981.tb03531.x

Stock, J., \& Watson, M. (1989). New Indexes of coincident and leading economic Indicators. In J. Olivier and Stanley Fisher (Eds.), NBER Macroeconomics Annual. Cambridge, Massachusetts. 


\section{Notes}

Note 1 . The theoretical literature argues that returns are negatively impacted by discount rate effects (inflation being a key macro factor) but positively affected by dividend effects (imminent economic expansion); see Nelson (1976).

Note 2. We thank Informa Global Markets for providing us with the MMS expectations data on PPI and CPI.

Note 3. In this regard it may be noted that the typical recession in the U.S. is about 11-month long.

Note 4. The main difference between deflation and low inflation is that during deflation the dividend effect may not easily turn positive for fear that the recession may last longer than usual. It is possible therefore for the dividend effect to stay negative for a long period.

Note 5. We note that the coefficient of inflation surprise is positive (significant at 10\%) in expansions in period VI when there are many mild deflation entries. This could be due to the fact that the usual negative discount rate effect in expansions is overturned because potential deflation likely implies further reductions in interest rates by the Federal Reserve. Indeed, the Federal Reserve had cut the Fed Funds rate down to 1\% which was then the lowest ever.

\section{Copyright Disclaimer}

Copyright for this article is retained by the author(s), with first publication rights granted to the journal.

This is an open-access article distributed under the terms and conditions of the Creative Commons Attribution license (http://creativecommons.org/licenses/by/3.0/). 